INTUISI $12(1)(2020)$
INTUISI
JURNAL PSIKOLOGI ILMIAH
$\begin{gathered}\text { http://journal.unnes.ac.id/nju/index.php/INTUISI } \\ \text { Terindeks DOAJ: 2541-2965 }\end{gathered}$

\title{
"NGOBROLIN SEKS" DALAM PERSEPSI PEREMPUAN PADA USIA DEWASA AWAL MENGGUNAKAN PENDEKATAN PSIKOLOGI INDIGENOUS
}

\author{
Anita Caroline ${ }^{\bowtie}$, Taufik Akbar Rizqi Yunanto
}

Fakultas Psikologi, Universitas Surabaya, Indonesia

\begin{tabular}{l}
\hline Info Artikel \\
\hline Sejarah Artikel: \\
Disubmit 26 Juni 2019 \\
Direvisi 9 Maret 2020 \\
Diterima 24 Maret 2020
\end{tabular}

Keywords:

Sexuality, Woman

Sexuality,

Reproductive Health,

Sex Education,

Indigenous Psychology

\begin{abstract}
Abstrak
Seksualitas melingkupi kehidupan manusia sejak lahir sampai sepanjang hidupnya. Seksualitas menyangkut berbagai dimensi, diantaranya dimensi kultural, sosial, biologis, dan psikologis. Namun isu seksualitas kerap dipandang tabu untuk diperbincangkan karena terkotak hanya pada pandangan sempit terkait perilaku seksual. Fenomena ini khususnya lebih sering ditemukan diantara perempuan dan kecenderungan ini dipengaruhi oleh identitas gender. Penelitian deskriptif ini bertujuan untuk mengidentifikasi bagaimana persepsi perempuan Indonesia dalam menguraikan tentang konsep seksualitas. Pengumpulkan data diambil dari 293 partisipan perempuan yang diperoleh melalui sampling acak, 88 partisipan telah menikah dan 205 partisipan belum menikah pada jarak usia 18 - 40 tahun. Berdasarkan hasil dari angket terbuka menunjukkan bahwa istilah seksualitas masih cenderung dipandang sebagai suatu hal yang tabu untuk dibicarakan $(40,96 \%)$ oleh perempuan Indonesia. Sekitar seperlima bagian $(21,16 \%)$ memandang bahwa seksualitas sebagai sesuatu yang wajar untuk dibicarakan jika sesuai dengan konteks dan berada dalam situasi tertentu. Sedangkan sisanya $(37,88 \%)$ beranggapan bahwa seksualitas bukanlah hal yang tabu untuk didiskusikan. Jika dijabarkan dikategorikan berdasarkan dimensinya, 23,89\% mencakup dimensi biologis, 10,58\% mencakup dimensi psikologis, 11,6\% mencakup dimensi sosial / kultural dan 53,93\% mencakup dimensi perilaku. Adapun harapannya adalah agar dapat bermanfaat untuk meningkatkan kesadaran akan pentingnya pendidikan seksualitas yang komprehensif.
\end{abstract}

\begin{abstract}
Sexuality covers human life from birth to throughout his life. Sexuality involves a wide range of dimensions, such as: biological, social / cultural, psychological, and behavior dimensions. But the issue of sexuality is often seen as taboo to be discussed because it is compartmentalized only in the narrow view of sexual behavior. This phenomenon is particularly common among women and this tendency is influenced by gender identity. This descriptive study aims to identify how Indonesian women perceive in describing the concept of sexuality. Collecting data was taken from 293 female participants obtained through random sampling, 88 married participants and 205 unmarried at the age range of 18-40 years. Based on the results of the open questionnaire, the term sexuality still tends to be seen as a taboo thing to talk about (40.96\%) by Indonesian women. While (21.16\%) the rest view sexuality as something natural to talk about if it is appropriate to the context and in certain situations. And only a small percentage (37.88\%) think that discussing sexuality is no longer a taboo thing to talk about. If described as categorized by dimensions, $23.89 \%$ includes the biological dimension, $10.58 \%$ includes the psychological dimension, $11.6 \%$ includes the social / cultural dimension and $53.93 \%$ includes behavior dimension. The hope is that it can be useful to increase awareness of the importance of comprehensive sexuality education.
\end{abstract}

(C) 2020 Universitas Negeri Semarang

\footnotetext{
Alamat korespondensi:

Fakultas Psikologi, Universitas Surabaya, Kampus Tenggilis,

Surabaya, Indonesia

anita.caroline@rocketmail.com
} p-ISSN 2086-0803 


\section{PENDAHULUAN}

Apa yang terlintas dalam benak Anda ketika mendengar kata "seksualitas"? Berbagai pandangan tentunya akan muncul terkait dengan isu tersebut. Seksualitas merupakan bagian integral dari kehidupan manusia. Lingkupan seksualitas suatu yang lebih luas dari pada hanya sekedar kegiatan hubungan fisik seksual.

Dengan pemahaman yang ada, semakin dimengerti bahwa seksualitas dapat menyangkut berbagai aspek dalam kehidupan. Seksualitas melingkupi kehidupan manusia sejak lahir sampai sepanjang hidupnya. Kondisi seksualitas menunjukkan kualitas kehidupan manusia yang terkait dengan perasaan dan keintiman, juga penerimaan dan ekspresi diri. Seks adalah perbedaan biologis manusia, atau yang sering disebut dengan jenis kelamin yaitu penis untuk laki-laki dan vagina untuk perempuan. Sedangkan seksualitas sendiri menyangkut dimensi yang luas, yaitu biologis, psikologis, sosial, dan perilaku. Seksualitas dari dimensi biologis berkaitan dengan organ reproduksi, termasuk pemeliharaan kesehatan dan optimalisasi fungsi organ reproduksi. Seksualitas dari dimensi psikologis erat kaitannya dengan fungsi manusia sebagai mahluk seksual, identitas peran, dan jenisnya. Dari dimensi sosial terkait pada bagaimana seksualitas muncul dalam hubungan interpersonal, bagaimana pengaruh budaya dalam membentuk pandangan seksualitas. Dimensi perilaku membahas bagaimana seksualitas ditunjukkan dalam perilaku seksual, yaitu perilaku yang muncul berkaitan dengan dorongan atau hasrat seksual (BKKBN, 2012).

Di Indonesia, berbicara tentang seksualitas masih merupakan hal yang tabu (Kristanti \& Dinastuti, 2017). Umumnya, kata "seksualitas" terbatas hanya pada perilaku seksual saja, sehingga menjadi tabu untuk diperbincangkan. Dengan begitu, umumnya orang mencari tahu seksualitas secara sembunyi - sembunyi tanpa pengawasan pendidik, misalnya melalui media. Hal ini menyebabkan pendidikan seksualitas dan kesehatan reproduksi yang ada tidak reliabel dengan realita perilaku seksual dan resiko seksual yang ada (Pakasi \& Kartikawati, 2013).

Dengan budaya patriarki yang masih langgeng berkembang di tatanan masyarakat Indonesia mengakibatkan munculnya berbagai masalah sosial yang membelenggu kebebasan perempuan dan melanggar hak-hak yang seharusnya dimiliki oleh perempuan (Sakina \& Siti A, 2017). Hal ini juga berdampak terhadap seksualitas perempuan. Demi kepentingan patriarkis, seksualitas perempuan dimaknai berdasarkan perspektif laki-laki dan dikonstruksikan dalam seksualitas yang pasif (Munfarida, 2010).

$$
\text { Impett \& Peplau }
$$

berpendapat bahwa sosialisasi peran gender konvensional menimbulkan perilaku patuh, termasuk kepatuhan perempuan dalam konteks seksual. Dalam masyarakat, 'feminitas ideal' bagi perempuan diasosiasikan dengan kecantikan, perilaku memelihara, dan pengorbanan diri. Definisi ini cenderung mempengaruhi perempuan untuk mengembangkan identitas mereka untuk memenuhi kebutuhan orang lain dan berperilaku sebagai penjaga umum yang tujuan utamanya adalah memberikan dukungan emosional (Hyde \& Else-Quest, 2013; Impett \& Peplau, 2003).

Dari hasil wawancara yang dilakukan penulis kepada salah satu perempuan Indonesia yang berusia 25 tahun dan belum menikah, diketahui bahwa masih ada konstruksi sosial yang membuat seksualitas sebagai bagian dari hak reproduksi ternyata tak bisa leluasa diekspresikan oleh perempuan. Ketidakadilan berperilaku sebagai makhluk 
seksual tersebut membatasi kebutuhannya untuk mengenal dan mengerti tentang tubuhnya sendiri. Padahal otonomi seksual dan reproduktif adalah hak asasi setiap manusia, seharusnya diberikan utuh kepadanya.

"Siklus menstruasiku tuh memang gak lancar dari dulu. Trus pernah suatu waktu aku tuh gak datang bulan hampir 3 bulan, jadi akhirnya mutusin buat ngecek ke dokter kandungan bareng mama. Pas lagi nunggu nomor antrian, ada ibu-ibu gitu, ngajakin mama ngobrol nanyain aku hamil berapa bulan. Dijelasin kan sama mama kalau mensku tuh gak lancar, tapi muka dia kayak gak percaya gitu. Trus bisik-bisik sama sebelahnya, mungkin dipikirnya aku MBA (marriage by accident) kali ya.. Trus pas udah masuk ke ruangan dokternya lebih parah lagi, padahal samasama cewek loh.. Masa ngomongnya gini, "Yakin ini belum pernah berhubungan intim? Ya udah, saya bikinkan resep, tapi yang kayak gini biasanya kalau sudah menikah, nanti bakal normal sendiri kok siklus menstruasinya." Gimana gak jengkel ya, habis itu aku sama mama mutusin buat ngecek ke dokter kandungan lain aja." $R$

Ketimpangan dalam menilai perilaku seksualitas merupakan salah satu cacat gender di masyarakat kita. Tidak banyak perempuan yang berani tampil di muka umum dalam berekspresi. Cacat gender seperti ini sebenarnya bisa saja diperbaiki, asal ekspresi seksualitas perempuan diberikan wadah yang aman. Sayangnya, ruang diskusi tentang seks masih sangat jarang, sehingga orang-orang masih menganggap ranahnya cuma dalam batas rumah tangga - harus berada dalam frame pernikahan.

Menurut Desmita (2012), persepsi merupakan salah satu aspek kognitif manusia yang memungkinkan seseorang untuk mengetahui dan memahami dunia sekelilingnya. Persepsi adalah proses pemberian arti terhadap lingkungan oleh individu. Sehingga setiap individu dapat memaknai stimulus secara berbeda meskipun objeknya sama (Khairani, 2013). Persepsi juga didefinisikan sebagai serangkaian proses internal yang memungkinkan seseorang dalam memperoleh, menafsirkan, dan menginterpretasikan informasi alat indera dari lingkungan sekitar. Interpretasi tersebut yang kemudian akan mempengaruhi seseorang dalam berperilaku (Ling \& Catling, 2013).

Persepsi perempuan Indonesia terkait konsep seksualitas dapat didefinisikan sebagai proses pemberian arti yang dimulai dari memperoleh, menafsirkan, dan menginterpretasikan konsep seksualitas oleh perempuan Indonesia. Studi saat ini berfokus pada isu seksualitas dalam masyarakat Indonesia dari perspektif perempuan, khususnya mengenai dilema dan konflik yang menantang mereka dalam mempertimbangkan antara kebebasan mereka melawan batasan-batasan sosial (Kristanti \& Poerwandari, 2018).

Penelitian deskriptif ini bertujuan untuk mengidentifikasi bagaimana persepsi perempuan Indonesia dalam menguraikan tentang konsep seksualitas. Adapun harapannya adalah agar dapat bermanfaat untuk meningkatkan kesadaran akan pentingnya pendidikan seksualitas yang komprehensif. 


\section{METODE}

Pengertian seks dan seksualitas sering kali digunakan secara salah kaprah dalam kehidupan sehari-hari. Seks merupakan perbedaan biologis laki-laki dan perempuan yang sering juga disebut dengan jenis kelamin. Sedangkan seksualitas mencakup lingkupan yang lebih luas dan menyangkut berbagai dimensi dalam kehidupan, yaitu biologis, psikologis, sosial, serta perilaku. Namun seksualitas masih sering dilihat secara terbatas hanya melalui dimensi perilaku saja, sehingga menjadi tabu untuk diperbincangkan.

Fenomena ini khususnya lebih sering ditemukan diantara perempuan karena budaya patriarki yang masih langgeng berkembang dalam tatanan masyarakat Indonesia. Perempuan lebih rentan mengalami ketidakadilan karena identitas gendernya. Sehingga definisi operasional dari persepsi perempuan Indonesia dalam memperbincangkan isu seksualitas adalah hasil interpretasi perempuan Indonesia mengenai isu seksualitas yang mempengaruhi perilaku mereka dalam memperbincangkannya dalam kehidupan sehari-hari.

Penelitian ini mengarah kepada indigenous psychology untuk mengeksplorasi dan memahami persepsi perempuan Indonesia dalam menguraikan tentang konsep seksualitas. Penelitian ini didesain dengan menggunakan metode kuantitatif dengan studi deskriptif. Pengumpulkan data diambil dari 293 partisipan perempuan yang diperoleh melalui sampling acak, 88 partisipan yang telah menikah dan 205 yang belum menikah yang berusia dewasa awal, yaitu: pada jarak usia 18 - 40 tahun. Mereka semua merupakan Warga Negara Indonesia (WNI) dengan suku etnis yang beragam dan tinggal di berbagai daerah di Indonesia.

Teknik pengumpulan data dilakukan dengan menggunakan angket terbuka. Penggunaan angket terbuka dipilih agar responden mempunyai kebebasan untuk memberikan jawaban. Pertanyaan terbuka terdiri dari 5 pertanyaan utama, yaitu: (1) "Hal apa yang terlintas pertama kali di benak Anda ketika mendengar kata seksualitas?"; (2) "Jelaskan definisi seksualitas secara sederhana menurut Anda!"; (3) "Bagaimana perasaaan Anda ketika membicarakan hal-hal terkait seksualitas di lingkungan sekitar Anda? Mengapa Anda merasa demikian?"; (4) "Apakah Anda pernah mendapatkan seks edukasi (formal) sebelumnya? Jika pernah, kapan? Di mana? Dan seberapa bermanfaat bagi Anda?"; dan (5) "Jika Anda memiliki pertanyaan terkait seksualitas, darimanakah biasanya Anda mendapatkan informasi untuk menjawab keingintahuan Anda?".

Hasil pengumpulan data dari angket terbuka dianalisa menggunakan teknik analisis deskriptif yang melakukan analisis hanya sampai pada taraf deskripsi, yaitu menganalisis dan menyajikan fakta secara sistematik sehingga dapat lebih mudah untuk dipahami dan disimpulkan (Azwar, 2012).

\section{HASIL DAN PEMBAHASAN}

Berdasarkan hasil dari angket terbuka menunjukkan bahwa istilah seksualitas masih cenderung dipandang sebagai suatu hal yang tabu untuk dibicarakan oleh $(40,96 \%)$ Perempuan Indonesia. Sekitar seperlima bagian $(21,16 \%)$ memandang bahwa seksualitas sebagai sesuatu yang wajar untuk dibicarakan jika sesuai dengan konteks dan berada dalam situasi tertentu. Sedangkan sisanya $(37,88 \%)$ yang beranggapan bahwa berdiskusi mengenai seksualitas sudah bukan merupakan hal yang tabu untuk dibicarakan.

"Saya merasa selama tinggal di
Indonesia ada beberapa hal
yang masih dianggap tabu
untuk membicarakan tentang
seksualitas. Mungkin ada
beberapa faktor salah satunya
adalah budaya yang sudah
ada."-(Anonim)

"Saya merasa selama tinggal di Indonesia ada beberapa hal yang masih dianggap tabu untuk membicarakan tentang seksualitas. Mungkin ada adalah budaya yang sudah ada."-(Anonim) 


\begin{abstract}
"Ketika membicarakan seksualitas di lingkungan sekitar, saya merasa kurang nyaman karena warga sekitar pastiakan mengkaitkan pembicaraan seksual pada sesuatu yang negatif dan tabu." $-S$
\end{abstract}

Isu seksualitas juga masih cenderung dianggap sebagai 'hak eksklusif' bagi pasangan yang telah terikat dalam status pernikahan. Sedangkan bagi mereka yang belum menikah diasumsikan untuk tidak seharusnya mengerti tentang hal tersebut. Hal ini disebabkan karena seksualitas hanya dipersepsikan pada pandangan sempit terkait perilaku seksual saja.

"Sungkan. Masih merasa hal tersebut tabu karena saya pribadi belum menikah." $-D$

"Tergantung bicara dengan siapa, kalau dulu saat remaja atau single bicara dengan orangtua atau yang lebih tua biasanya lebih menjaga agar tidak telalu vulgar. Karena takut di cap terlalu banyak mengerti tentang seksualitas padahal belum menikah. Kalau sekarang dengan suami ya bebas bicara apapun tentang seksualitas agar saya dan suami saling memahami keinginan dan kenyamanan masing-masing." - (Anonim) "Jika mendengarkan atau diskusi secara umum oke, tetapi jika ditanya terkait pengalaman pribadi, lebih suka tidak menjawab, terutama dengan yang belum married." (Anonim)

Menurut Kristanti \& Poerwandari (2018), isu seksualitas, khususnya perilaku seksual sebelum menikah, masih merupakan hal yang tabu di Indonesia. Dari sudut pandang agama maupun budaya, perilaku seksual sebelum menikah dianggap sebagai penyimpangan sosial, tidak sehat, tidak bermoral, illegal dan berbahaya. Meskipun aturan ini berlaku bagi laki-laki maupun perempuan, konstruksi sosial sangat menitikberatkan pada perlindungan kesucian dan keperawanan perempuan. Seorang perempuan yang kehilangan keperawanannya sebelum menikah biasanya direndahkan dengan stigma dan terminologi seperti 'rusak', 'murahan' dan 'gampangan'.

'Moralitas' digunakan mengatur kehormatan perempuan, perilaku seksual perempuan harus terbungkus rapi oleh aturan dalam masyarakat, disembunyikan, tidak perlu dikeluarkan dari cangkangnya. Sayangnya, keadaan ini tidak disadari kebanyakan perempuan. Mereka ikhlas menyerahkan dirinya sebagai bagian dari masyarakat yang patuh terhadap bentuk 'moralitas' tersebut. Perempuan dianggap memiliki seksualitas yang lebih tertutup dan pasif, sedangkan laki-laki lebih bebas dalam mengekspresikannya (Ardiansyah, 2012).

"Apa ituuuu ngobrolin seks?

Aku masih di bawah usia dewasa.." - F

"Ihhhh ngobrolin seks.." $-M$

Beberapa partisipan memberikan respon serupa dengan nada bercanda dan bersikap malu-malu ketika diminta untuk mengisi angket terbuka. Memang perempuan cenderung menghindari membicarakan seks di muka umum untuk mengamankan dirinya.

"Canggung, karena takut dihakimi." $-L$

"Insecure dan takut dianggap perempuan nakal." - M

"Kurang nyaman. Takut dianggap wanita murahan." (Anonim)

"Takut dan ngehindar karena sudah pernah dibilang ih udah ga perawan'." - (Anonim)

"Merasa sensitif. Karena berhubungan dengan privasi seseorang lebih lagi saya seorang perempuan." $-K$ 
"Buruk. Saya tidak akan pernah bisa membicarakan seksualitas tanpa dianggap tabu, bahkan dianggap sedang horny dan 'minta ditiduri'." - An

"Secara pribadi biasa saja. Tapi berhubung 99,9\% respon nya selalu dianggap 'lagi sange' kalau bahas seks, jadi nggak akan pernah bahas lagi ke siapa-pun, terutama ke orang Indonesia." - AJ

"Dianggap perempuan ga baik sih. Masyarakat terlebih perempuan sendiri menganggap itu pembahasan yang saru (kotor dalam bahasa jawa) padahal untuk umur saya yang sebentar lagi 21tahun ini, itu bukan hal yang saru dan tabu untuk dibicarakan." - Ny

\section{Lofgren-Martenson \& Mansson} (2010) juga menekankan pentingnya memahami makna budaya dan signifikansi yang berkaitan dengan isu seksualitas. Mengetahui stigma negatif yang mungkin mereka dapatkan, perempuan enggan menggedor aturan masyarakat atau malah memilih bungkam saja daripada diserang cibiran. Karena blak-blakan soal seks sama saja mengarahkan diri ke unsafe behaviour yang sampai sekarang masih dijadikan dasar untuk menyalahkan korban pelecehan seksual (Tirto.id, 2018). Perempuan justru menjadi pihak yang disalahkan, terkait hal-hal seperti: cara berpakaian, tingkah laku, waktu kejadian pelecehan, atau justifikasi lainnya yang tidak menempatkan laki-laki sebagai pelaku (Sakina \& Siti A, 2017).

Menurut BKKBN (2012) seksualitas dapat dibagi ke dalam 4 dimensi, yaitu: (1) Dimensi biologis; (2) Dimensi psikologis; (3) Dimensi sosial atau kultural; dan (4) Dimensi perilaku.

Dimensi biologis berupa $23,89 \%$. Sekelompok partisipan mendefinisikan konsep seksualitas sebagai perbedaan jenis kelamin dan organ reproduksi, seperti yang ditunjukkan dalam sampel respon dibawah ini:

"Perbedaan antara pria dan
wanita berdasarkan ciri-ciri
biologis."-Ang
"Seksualitas berkaitan dengan
organ reproduksi dan alat
kelamin, termasuk bagaimana
menjaga kesehatan dan
optimalisasi fungsi organ
reproduksi dan dorongan
seksual."-MA

Dimensi psikologis berupa 10,58\%. Hanya sedikit dari partisipan yang mendefinisikan konsep seksualitas dari sisi psikologis yang mencakup konsep diri, aktualisasi diri, ekspresi, dan emosi, seperti: cinta dan kasih sayang. Hal ini ditunjukkan dalam sampel respon dibawah ini:

"Sesuatu yang di dalamnya menyangkut konsep diri, cinta, keintiman, identitas seksual serta orientasi seksual." - L

"Menurut saya itu bukti cinta yang seutuhnya." - Lia

"Cinta." - Puj

Dimensi sosial atau kultural berupa $11,6 \%$. Sekelompok kecil partisipan mendefinisikan konsep seksualitas melalui sudut pandang budaya dan agama yang ada Indonesia, seperti: berkat atau hadiah yang diberikan oleh Tuhan YME dan hanya boleh dilakukan dengan ikatan pernikahan. Hal ini ditunjukkan dalam sampel respon dibawah ini:

"Hadiah Tuhan yang diberikan bagi pasangan yang sudah menikah." - C

"Hubungan badan tanda persatuan yang sangat intim antara seorang pria dan wanita yang telah dipersatukan dan disahkan dalam pernikahan yang kudus / sakral." (Anonim)

"Hubungan seksual antara pria \& wanita yang seharusnya baru 


$$
\begin{aligned}
& \text { boleh dilakukan setelah } \\
& \text { menikah." }- \text { (Anonim) }
\end{aligned}
$$

Dimensi perilaku berupa 53,93\%. Lebih dari separuh partisipan mendefinisikan konsep seksualitas sebagai hubungan antar manusia yang akhirnya membentuk perilaku seksual, seperti yang ditunjukkan dalam sampel respon dibawah ini:

"Sebuah ketertarikan yang
berkaitan dengan hasrat
manusia terhadap lawan jenis."
- Mer
"Kegiatan seksual yang
dilakukan oleh 2 individu."-S
"Hubungan antar dua orang
untuk mengungkapkan
perasaan atau sekedar
memuaskan nafsu."-BJ

Sebagian besar dari partisipan sudah pernah mendapatkan pendidikan seksualitas secara formal, baik di bangku sekolah, mengikuti seminar, atau-pun melalui bimbingan pra-nikah. Namun, hanya sebagian $(35,49 \%)$ dari mereka yang benar-benar merasakan manfaatnya; bahkan beberapa sudah tidak ingat lagi apa yang telah didapatkan. Ada-pun yang mengemukakan bahwa ia merasa terlambat dalam mendapatkan pendidikan seksualitas.

"Saat SMA di sekolah (saya merasa agak terlambat saya mendapat seks edukasi secara formal, saya merasa semakin dini semakin baik). Sebenarnya sangat bermanfaat tetapi akan lebih baik jika orangtua sejak dini sudah memperkenalkan kepada saya." - (Anonim)

"Sewaktu SD kelas 5, kalau ga salah, guru saya pernah memberikan kelas terpisah antara murid laki-laki dan perempuan, Tetapi penyampaiannya hanya seputar perubahan tubuh karena pubertas. Kemudian saat SMP dan SMA belajar mengenai reproduksi tetapi tidak fokus pada seks edukasi." - Dy

Holzner \& Oetomo (2004) menyoroti kelemahan pendidikan seksualitas dan kesehatan reproduksi di sekolah selama ini cenderung bertujuan untuk menekan perilaku 'seks bebas' yang tidak sehat dan berbahaya saja. Pendidikan seksualitas di Indonesia belum komprehensif dan belum reliabel terhadap pelaku dan resiko seksualnya. Hal ini disebabkan karena pendidikan seksualitas terbatas pada aspek kesehatan reproduksi dan seksual remaja saja. Para pendidik terbatas pada fenomena biologisnya saja. Mereka juga cenderung mengkonstruksikan seksualitas sebagai hal yang tabu dan semata - mata dikontrol melalui moral dan agama (Pakasi \& Kartikawati, 2013).

"Sekitar tahun 2008-2009, di
sekolah (SMP). Sangat
bermanfaat karena saya bisa
belajar tentang dampak negatif
free sex dan mengetahui segala
jenis penyakit kelamin. - E
"Di SMA, mendapatkan
informasi mengenai perilaku
seksual (kejahatan) yang marak
terjadi disekitar kita, dapat
membatasi diri sendiri agar
tidak terjerumus dalam seks
bebas."-E
"SMP, kurang bermanfaat
karena guru hanya menjelaskan
efek pergaulan bebas." $-T$

Konsep pendidikan seksualitas yang komprehensif tidak cukup hanya berupa pemberian pengetahuan saja, namun juga perlu diberi kesempatan agar mampu mengembangkan keterampilan, sikap dan nilai-nilai yang dibutuhkan untuk menentukan seksualitas sebagai individu maupun dalam berelasi secara fisik maupun psikis. Pendidikan seksualitas yang komprehensif juga perlu memperhatikan konteks sosial budaya yang ada (Pakasi \& Kartikawati, 2013). 
Cara mendapatkan informasi untuk menjawab keingintahuan terkait isu seksualitas, para partisipan akan mencari dengan berselancar di internet $(66,49 \%)$, serta $(16,23 \%)$ bertanya atau berdiskusi dengan teman, kerabat, atau orang yang dianggap sudah lebih berpengalaman. Hanya sebagian kecil $(17,28 \%)$ yang mencari tahu melalui media atau orang yang dapat diandalkan, seperti: dokter atau psikolog. Seiring berkembangnya jaman dan teknologi juga mempermudah untuk menemukan informasi yang dapat diandalkan. Beberapa lembaga sosial atau pekerja professional menggunakan sosial media sebagai media untuk berbagi ilmu yang akurat dan dapat diandalkan.

"Google saat jaman sekolah, kalau sekarang banyak informasi yang dibagikan langsung oleh dokter, psikolog dan psikiater di sosial media. Tapi tetap lebih baik tanya langsung pada yang ahlinya." (Anonim)

"Komunitas/ individu yang memang memberikan informasi tentang seksualitas, misal: IG (instagram)@inezkristanti, @catwomanizer,@tabuid,dll." - (Anonim)

\section{SIMPULAN}

Hasil penelitian ini menunjukkan bahwa isu seksualitas masih cenderung menjadi hal yang tabu untuk dibicarakan oleh Perempuan Indonesia, terutama bagi mereka yang belum menikah, karena hanya dipersepsikan pada pandangan sempit terkait perilaku seksual saja. Maka dapat disimpulkan bahwa pendidikan seksual yang komprehensif merupakan hal yang sangat penting, terutama dalam rangka untuk membentuk suatu wadah yang aman bagi Perempuan Indonesia dalam mendapatkan pendidikan seksualitas dan informasi terkait seksualitas-nya secara pribadi.

Konstruksi dan wacana mengenai pendidikan seksualitas memiliki peran penting terhadap isi dan metode pendidikan seksualitas. Tidak hanya hal tersebut, namun kesehatan reproduksi bagi perempuan Indonesia juga dipengaruhi oleh kedua faktor di atas. Konstruksi seksualitas perempuan Indonesia perlu dipaparkan dalam pendidikan seksualitas, yang juga terkait dengan kesehatan reproduksi. Perempuan Indonesia perlu diedukasi bahwa mereka adalah makhluk seksual yang dapat mempertanggungjawabkan fungsi seksual dan kesehatan seksualnya secara positif. Hal tersebut jg perlu dikaitkan dengan kenikmatan seksual, beserta dengan dampak resiko seksualnya. Dengan demikian, maka pendidikan seksualitas pada perempuan Indonesia akan lebih efektif.

Saran penulis bagi penelitian berikutnya adalah untuk meneliti secara lebih mendalam mengenai realitas perilaku seksual dan resiko seksual yang mungkin dapat dihadapi oleh Perempuan Indonesia sebagai akibat dari kurangnya pendidikan seksualitas yang komperhensif. Sehingga dapat memberikan peran penting terhadap terhadap isi dan metode pendidikan seksualitas yang akan dikembangkan di masa depan.

\section{DAFTAR PUSTAKA}

Ardiansyah, A. S. (2012). Konstruksi Seksualitas Perempuan di Majalah Men's Health. Jurnal Komunikator, 4(2), 81-92.

Azwar, S. (2012). Metode Penelitian. Yogyakarta: Pustaka Pelajar.

Badan Kependudukan dan Keluarga Berencana Nasional (BKKBN). (2012). Genre Goes To School: Yang Muda Harus Berencana. Ditemu kembali dari:

http://www.bkkbn.go.id/_layouts/mobil eldispform.aspx? List=f933abed-281441559570ed3d22$76 b 169 \&$ View $=752 b d f 84-8082-49 c e-$ $8654-7 d 312 f 11 c 5 d b \& I D=7$ 
Desmita. (2012). Psikologi Perkembangan Peserta Didik. Bandung: Remaja Rosdakarya.

Holzner, B. M., \& Oetomo, D. Y. (2004). Youth, sexuality and sex education messages in Indonesia: issues of desire and control. Reproductive Health Matters, 12(23), 40-49.

Hyde, J. S., \& Else-Quest, N. (2013). Half the human experience: The psychology of women (ed. 8). Belmont, CA: Wadsworth, Cengage Learning.

Impett, E.A., \& Peplau, L. A. (2003). Sexual compliance: Gender, motivational, and relationship perspectives. The Journal of Sex Research, 40(1), 87-100.

Khairani, M. (2013). Psikologi Umum. Yogyakarta: Aswaja Pressindo.

Kristanti, I., \& Dinastuti. (2017). Faktorfaktor pendukung pornography distress pada istri pengguna pornografi. Jurnal Psikologi Indonesia, 7(1), 1-18.

Kristanti, I., \& Poerwandari, E. K. (2018). Premarital Sexual Compliance among Urban Indonesian Women: A Descriptive Study. Psychological Research on Urban Society, 1(1), 2637.
Ling, J., \& Catling, J. (2013). Psikologi Kognitif. Jakarta: Erlangga.

Lofgren-Martenson, L., \& Mansson, S. -A. (2010). Lust, Love, and Life: A Qualitative Study of Swedish Adolescents' Perceptions and Experiences with Pornography. Journal of Sex Research, 47(6), 568-579.

Munfarida, E. (2010). Seksualitas Perempuan dalam Islam. Jurnal Studi Gender \& Anak, 5(2), 368-397.

Pakasi, D.T., \& Kartikawati R. (2013) Antara Kebutuhan dan Tabu: Pendidikan Seksualitas dan Kesehatan Reproduksi bagi Remaja di SMA. Makara Seri Kesehatan, 17(2), 79-87.

Putri, A. W. (2018, Mei 19). 2018 Jadi Tahun yang Buruk Bagi Korban Kekerasan Seksual. Tirto.id. Retrieved from: https://tirto.id/2018-jadi-tahun-yangburuk-bagi-korban-kekerasan-seksual$d c K w$

Sakina, A.I., \& Siti A., D.H. (2017). Menyoroti Budaya Patriarki di Indonesia. Social Work Jurnal, 7(1), 71-80. 